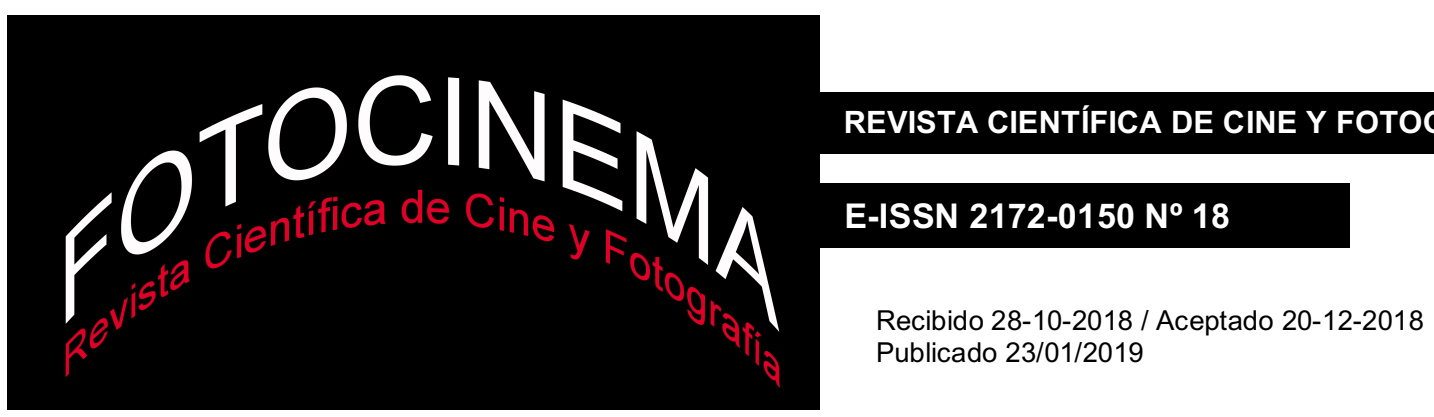

\title{
Cine y multilingüismo en la abadía subtitulada de Jean-Jacques Annaud
}

\section{Cinema and multilingualism in the subtitled abbey of Jean- Jacques Annaud}

\author{
Fran Mateu \\ Universidad de Alicante / ESRP, centro adscrito a la Universidad de Barcelona, España \\ fran.mateu@esrp.net
}

\section{Resumen:}

En el presente texto se repasan algunos conceptos básicos acerca de la traducción audiovisual, sobre todo en lo referente al doblaje y subtitulación. Por otro lado, se hace alusión al cine multilingüe, en cuyas historias conviven diversas lenguas. Cuando se exhibe a nivel internacional, el contenido de esta modalidad de cinematografía no suele ser doblado en su totalidad, aplicándose la traducción, generalmente, sobre el idioma principal de la película. Los motivos suelen ser diversos, sobre todo en relación al tipo de historia que se cuenta al espectador, pudiendo alterar la esencia de la obra. Asimismo, en el texto se plantea, como breve estudio de caso, la película El nombre de la rosa (Der name der rose, JeanJacques Annaud, 1986), cuyo multilingüismo define su verosimilitud, contextualización histórica y narratología.

\section{Abstract:}

In this text, some basic concepts of audiovisual translation are reviewed, especially in relation to dubbing and subtitling. On the other hand, reference is made to multilingual cinema, in whose stories coexist different languages. When this is internationally exhibited, the content of this kind of cinematography isn't usually dubbed in its entirety, applying the translation, generally, on the main language of the film. The reasons are often diverse, especially in relation to the kind of story that is shown to the audience, and that may alter the essence of the film. Likewise, the film The name of the rose (Der name der rose, Jean-Jacques Annaud, 1986) is introduced as a brief case study in this paper, whose multilingualism defines its verisimilitude, historical contextualization and narratology.

Palabras clave:

Cine; multilingüismo; doblaje; subtitulación; traducción; audiovisual.

Keywords:

Cinema; Multilingualism; Dubbing; Subtitling; Translation; Audiovisual. 


\section{El doblaje y la subtitulación en la traducción audiovisual}

El semiólogo Umberto Eco dijo que la traducción concernía a mundos posibles; y que a la hora de traducir un texto, se debía formular la hipótesis más plausible, vertiendo el texto de una lengua a otra del modo más adecuado, siendo un proceso que nunca era neutral, pues debía existir una negociación entre las partes (2003, p. 10). Los mundos posibles de Umberto Eco también se expanden al ámbito de la traducción audiovisual, donde la simultaneidad de códigos producen nuevos encuentros. Bajo este aspecto, Frederic Chaume define la traducción audiovisual como una tipología de traducción caracterizada por la particularidad de los textos objeto de la transferencia interlingüística, los cuales procesan información mediante el canal visual y auditivo (2004, p. 30). Así, la traducción altera el código lingüístico del canal verbal de la obra audiovisual o agrega un código textual gráfico a dicho contenido, siendo procesos subordinados a la imagen. Esta subordinación da lugar a que la traducción audiovisual no se centre exclusivamente en modificar el idioma original de la obra, ya que el mensaje final está integrado junto con la imagen, y se debe tener en cuenta todo lo que aparezca en pantalla. Como indica Teresa Carriles, hay situaciones en las que los personajes dicen algo, pero sus caras están expresando lo contrario, por lo que conviene contar con la imagen, ya que condiciona la traducción (2016, p. 12). Por ello, aunque la obra se componga de códigos visuales, sonoros y gráficos, la imagen determina los matices traductológicos:

[...] la regla principal por la que todo traductor audiovisual debe regirse es la de «la imagen manda». Esto significa que no puede traducir un guion escrito sin fijarse también en la película o serie para ver si coinciden o si tiene algún matiz distinto (Carriles, 2016, p. 17).

$\mathrm{Al}$ definir la traducción audiovisual como una transferencia interlingüística (en este caso, del texto cinematográfico ${ }^{1}$ ), ésta se desarrolla, principalmente, a través del doblaje y la subtitulación². Mabel Richart define el doblaje del siguiente modo:

\footnotetext{
${ }^{1}$ También concierne a otros productos culturales, como los videojuegos o las machinimas.

2 Además de otros procesos, como la voz superpuesta (frecuente en documentales, discursos o entrevistas); o la audiodescripción y la subtitulación descriptiva, para personas con discapacidad visual $\mathrm{o}$ auditiva.
} 
El doblaje es un proceso de expansión cultural y comercial consistente en la traducción, moldeamiento y transformación de la dimensión verbal de un film en sincronía con los labios de los actores y actrices, la dramatización, el tiempo de los discursos y la trama, y en cuya realización intervienen diferentes agentes (Richart, 2008, p. 303).

Como señala Rosa Agost, el doblaje continúa siendo la modalidad más aceptada en España, sobre todo por una cuestión de inercia y comodidad, a pesar de que el consumo de obras subtituladas comienza a estar cada vez más aceptado por el público (2007, pp. 302-303). Sin embargo, y como indican David Bordwell y Kristin Thompson, la anulación del doblaje, visionando la obra en su lengua original, tiende a ser el modelo mejor valorado, sobre todo en circuitos menos comerciales y para los estudiosos de la cinematografía:

La eliminación de las voces de los actores originales suprime un importante componente de su interpretación. [...] Con el doblaje, todos los problemas habituales de traducción se multiplican debido a la necesidad de sincronizar palabras concretas con movimientos específicos de los labios (Bordwell \& Thompson, 2003, pp. 331-332).

No obstante, el doblaje no debe tratarse como el mayor de los males, pues bajo determinadas circunstancias puede ayudar a expandir una obra audiovisual. Respecto a los subtítulos, como apunta Marcel Martin, la dicotomía entre palabra e imagen ha estado presente, prácticamente, desde los inicios del cine:

[...] las películas mudas estaban llenas de intertítulos cuya palabrería siempre interrumpía la continuidad de las imágenes. Al hacerse sonoros, los diálogos plantearon problemas técnicos de traducción simultánea: los subtítulos constituyeron la solución menos mala (Martin, 2002, p. 187).

Su visión respecto a los intertítulos, que evolucionaron a los actuales subtítulos, no es excesivamente positiva si contaminan la naturaleza del lenguaje audiovisual. Entre ambos elementos existen matices, ya que, como señala Frederic Chaume, los intertítulos nacieron con un carácter intralingüístico, leyéndose en la misma lengua en la que se había realizado la obra original, mientras que los subtítulos poseían una cualidad interlingüística, apareciendo en un idioma diferente (2004, p. 44). Así, los subtítulos son códigos interlingüísticos presentes en la parte inferior de la imagen, los cuales traducen, a través de texto 
escrito, lo que, por lo general, hablan los personajes, teniendo en cuenta otras consideraciones que indica Francisca García:

Los subtítulos pueden contener un máximo de dos líneas, cada una de las cuales incluirá un número máximo de caracteres que oscila entre los 35 y los 40. La razón para esta restricción la encontramos tanto en la velocidad de lectura del espectador como en la necesidad de respetar en lo posible la integridad de la imagen (García, 2002, p. 172).

Este número máximo de caracteres es una restricción subordinada a la naturaleza audiovisual de la obra. Como señala Núria Martínez, los subtítulos se ayudan de los sonidos e imágenes de la lengua original, pero surgen dificultades como la síntesis, la condensación, la neutralización, la segmentación o la omisión de éstos con el objetivo de respetar el número máximo de caracteres que el ojo es capaz de seguir (2008, p. 7). En relación a las restricciones de la traducción audiovisual, José Luis Martí enuncia seis posibilidades: profesionales (preliminar a la traducción, por las condiciones laborales del encargo), lingüísticas (como el uso de dialectos), formales (por ejemplo, si se requiere sincronía fonética), semióticas (o icónicas, relacionadas con el carácter visual de la obra), socioculturales (en relación a la coexistencia de diversos sistemas culturales en la obra) y nulas, en el caso de no existir (2010, pp. 83-86). Una vez abordadas las diferentes restricciones, el traductor debe ofrecer al público una obra que se perciba como un todo. Como apunta Teresa Carriles, la labor principal del traductor es conseguir que el receptor no perciba que está consumiendo una traducción, y cuando se cumple el objetivo, ésta parece natural, espontánea e idiomática, aunque no siempre sea correcta desde una perspectiva lingüística (2016, p. 14). Por ello, el doblaje y la subtitulación son procesos traductológicos cuyas características y restricciones generan un debate constante, encontrando, por ejemplo, la perspectiva prescriptivista y la descriptivista. Como señala Carla Botella, la primera de ellas considera que la subtitulación y el doblaje son procesos de adaptación, ya que no reflejan de forma fidedigna la obra original, la cual posee una única traducción posible:

[...] las características propias de la subtitulación (condensación, segmentación y síntesis) y del doblaje (ajuste y sincronismo) impiden la fidelidad absoluta al texto original que reclama la escuela prescriptivista. El hecho de estar subordinada a la 
imagen, ya de por sí, convierte a este tipo de traducción, a ojos de prescriptivistas, en adaptación (Botella, 2007, p. 11).

Sin embargo, desde una perspectiva descriptivista, el doblaje y la subtitulación se reciben como traducciones (Botella, 2007, p. 12). La mentalidad prescriptivista acude a una única traducción que refleje la identidad de la obra de manera formal, pero los descriptivistas consideran que un texto posee tantas traducciones como una sociedad pueda aceptar, y el traductor debe adaptarse a las diferentes variables, como el contexto, las exigencias del público o las restricciones del medio, por lo que la traducción no es formal (a diferencia de la premisa prescriptivista), pudiendo alterar el contenido de la obra (Botella, 2007, p. 8). Así, se puede considerar el proceso de adaptación como una práctica intrínseca de la traducción bajo una perspectiva descriptivista, mientras que el prescriptivismo diferenciaría un proceso respecto al otro3. En consecuencia, la vertiente descriptivista da lugar a que, en la actualidad, el traductor sea, como apunta Teresa Carriles, una figura polifacética, pues debe desenvolverse en cualquier ámbito, además de adaptarse a los constantes cambios (2016, p. 13). Se trata de unos rasgos distintivos que se alejan del prescriptivismo formal inicial.

\section{La traducción audiovisual en el cine multilingüe}

En la actualidad, es frecuente encontrarnos con personas capaces de comunicarse en más de una lengua. De hecho, la cantidad de población que habla más de un idioma va en aumento (Brychová, 2017, p. 123). El cine se hace eco de ello, y como apunta Carmen Cuéllar, "en el actual mundo globalizado, el multilingüismo está cada vez más presente en el cine" (2018, p. 601). Cuando la obra es multilingüe, surgen nuevos matices traductológicos. Sin embargo, conviene diferenciar entre películas multilingües y versiones multilingües, siendo estas últimas una modalidad de traducción surgida en la década de 1930 que, como señala Montserrat Mendoza, consiste en una cuarta alternativa (más allá de consumir la obra en versión original, subtitulada o doblada), donde la película se grababa en diferentes idiomas para complacer a la mayor cantidad de público posible,

3 En un sentido cronológico, el prescriptivismo dio lugar al posterior prescriptivismo funcionalista, donde el principio de identidad se consideraba una aspiración idealista, y cuyas ideas desembocaron en el descriptivismo (Botella, 2007, p. 11). 
aunque los avances tecnológicos permitieron que el doblaje se terminara imponiendo (2015, pp. 10-11). Por otro lado, y como define Jorge Díaz-Cintas, "las películas multilingües o plurilingües son aquellas en las que uno o varios personajes hablan, como mínimo, dos lenguas distintas" (2015, p. 137). A la hora de decidir cómo traducir el cine multilingüe4, Montse Corrius y Patrick Zabalbeascoa denominan L1 (o lengua origen) al idioma que aparece en la obra original, L2 (o lengua meta) al idioma en que aparece traducido, y L3 a las terceras lenguas (inventadas o no, apareciendo de forma oral o escrita) que tengan presencia en la obra (2011, p. 113). Para traducir L3, ambos autores proponen diferentes posibilidades a través de un diagrama (F1), en el que L ${ }^{\mathrm{TT}}$ es la L3 de la lengua meta y L3 ${ }^{\mathrm{ST}}$ es la L3 de la lengua origen:

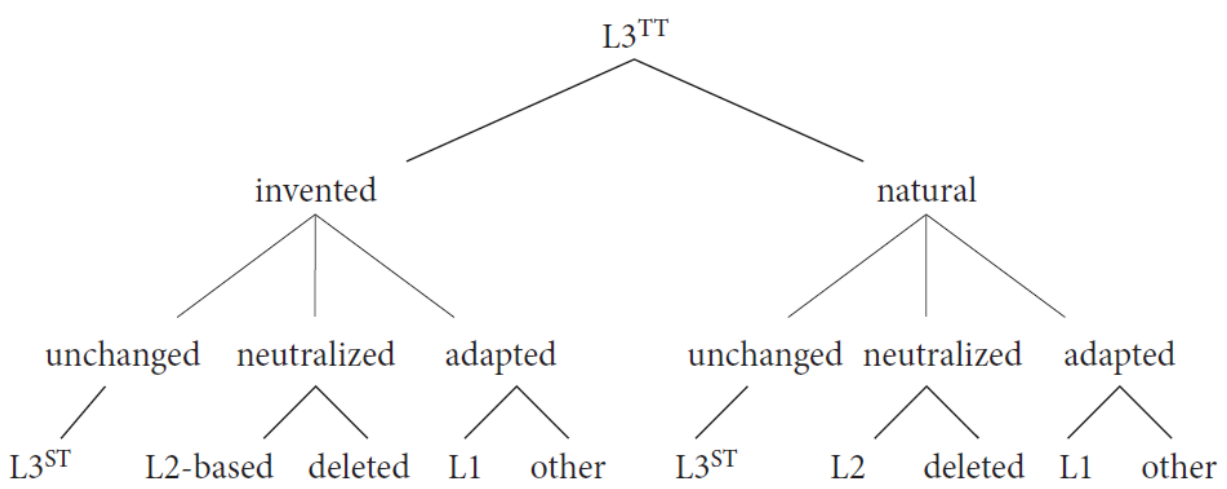

F1. Diagrama de las posibles traducciones de L3 (Corrius \& Zabalbeascoa, 2011, p. 120).

Así, L3 $3^{\mathrm{TT}}$ puede coincidir con $\mathrm{L}_{3}^{\mathrm{ST}}$ (sin aplicar cambios), puede neutralizarse (traduciéndose a L2 o eliminándose), o puede adaptarse (traduciéndose a L1 o a cualquier otra lengua). Respecto a las lenguas inventadas L3 ${ }^{\mathrm{ST}}$, éstas pueden estar basadas en L1, sobre todo cuando las expresiones son relevantes o informativas (haciéndolas más comprensibles), o pueden contener otra lengua natural (diferente a L1) como base (Corrius \& Zabalbeascoa, 2011, p. 117). Así, otro tipo de mundo posible lo encontramos en obras audiovisuales cuyo multilingüismo da lugar a la necesidad de subtítulos por la aparición de lenguas inventadas. Bajo este aspecto, cabe recordar al profesor J.R.R. Tolkien, creador de diversas lenguas

4 Presente en títulos como Lost in translation (Sofia Coppola, 2003), La terminal (The terminal, Steven Spielberg, 2004), La última primavera (Ladies in Lavender, Charles Dance, 2004), Babel (Alejandro González Iñárritu, 2006), Malditos bastardos (Inglorious basterds, Quentin Tarantino, 2009), u Overlord (Julius Avery, 2018), entre otros. 
para las distintas razas de la Tierra Media, considerado uno de los principales referentes de las artlangs y las conglangs:

Before Tolkien was an author, he was a philologist who is now considered the father of "artlangs" and "conlangs". The languages of Tolkien's Middle-earth [...] are highly regarded for their grammatical completeness and their ability to function as natural languages instead of artificial ones. [...] Artificial languages or "artlangs", have been popular for years ranging from Klingon found in Star Trek to Dothraki spoken in The Game of Thrones television series. [...] As the years have passed since Tolkien's death, many authors and linguists use Tolkien's Elvish as a bases for what are referred to as "conlangs" or "constructed languages" which began to appear in television series, films, and novels (Coker, 2016, pp. 1242-1249).

El multilingüismo del universo literario de J.R.R. Tolkien fue respetado, en la medida de lo posible, en las adaptaciones cinematográficas de Peter Jackson; y en este tipo de obras, la metodología de traducción adapta subtítulos (en L1 o L2) cuando los personajes se comunican en artlangs o conglangs 5 (salvo que se deseen omitir deliberadamente). Así, si la lengua origen es el inglés (L1), pero dentro de la trama aparece, como mínimo, una L3, es común que ésta aparezca igual tras un proceso de doblaje, leyéndose su traducción mediante subtítulos en L2. Sin embargo, el idioma original L1 (a nivel global dentro de la trama), se dobla a la lengua afín del país en el que la obra se exhibe. Por ello, se puede ver al elfo Légolas hablando en inglés (L1), o en español en la versión doblada (L2), con el hobbit Frodo, pero si el personaje habla en élfico (L3) con los de su raza, los espectadores tendrán a su disposición la traducción de lo que dice a través de subtítulos en inglés (adaptándose a L1) o en español (neutralizándose a L2), en su caso, pero no figurará el doblaje del idioma élfico. Se trata de mantener la esencia de la pluralidad de razas de la Tierra Media, coexistiendo más de una comunidad lingüística (pese al doblaje global inherente). También puede darse la situación, por ejemplo, de que un personaje pronuncie un diálogo en la lengua origen (o lengua meta, si ha habido un proceso de doblaje) y, a continuación, se repita en L3 (o viceversa); o que se traduzcan entre los mismos personajes, causando frecuentemente la omisión de subtítulos, pues se sobreentiende lo que se acaba de comunicar. Como señala Núria Martínez, en estos casos, lo habitual Besson, 1997), Avatar (James Cameron, 2009) o Alpha (Albert Hughes, 2018). 
es que no aparezcan subtítulos, ya que se está dando la misma información, sólo que en distintas lenguas, pudiendo resultar redundante (2008, p. 16). En consecuencia, este tipo de procesos también se aplican cuando la totalidad de lenguas presentes en la obra sí que existen o, al margen de su autenticidad, tienen un uso más limitado. Como indica Jorge Díaz-Cintas:

En los filmes políglotas el multilingüismo puede utilizarse con distintas finalidades y efectos diegéticos. [...] las lenguas demarcan fronteras geográficas y políticas y tienen también el potencial de simbolizar atributos sociales, culturales y personales de los distintos personajes. La diversidad lingüística es un recurso que remarca, como ningún otro, la identidad de los protagonistas y enfatiza su otredad (DíazCintas, 2015, p. 138).

Este carácter de identidad, otredad y diferenciación multilingüe se halla presente en El nombre de la rosa (Der name der rose, Jean-Jacques Annaud, 1986), tratándose del estudio de caso que se repasará de manera más pormenorizada a continuación pues, tanto la novela original de Umberto $\mathrm{Eco}^{6}$, así como la adaptación cinematográfica de Jean-Jacques Annaud, mantienen estos atributos. Aunque nos centraremos en la versión original de la obra, también se ofrecerán determinadas apreciaciones acerca de su doblaje en español7. Bajo estos aspectos, y desde una perspectiva de análisis inductiva, nuestra hipótesis inicial es que si se hubiesen adaptado la totalidad de lenguas presentes en la versión original de El nombre de la rosa a L1 (eliminando oralmente L3), o neutralizado todas ellas a L2 en su doblaje español, habrían desaparecido tres esencias básicas de la obra: su verosimilitud, su contextualización histórica y su narratología.

\section{Sobre la historia de El nombre de la rosa}

La trama de la adaptación cinematográfica de El nombre de la rosa sitúa al espectador a finales del mes de noviembre de 1327, dentro del período conocido como la Baja Edad Media. El monje franciscano inglés Guillermo de Baskerville (interpretado por Sean Connery), y su novicio, el joven alemán Adso de Melk (interpretado por Christian Slater), llegan a una abadía benedictina ubicada en el

\footnotetext{
${ }^{6} \mathrm{cfr}$. Il nome della rosa (Eco, 1980).

7 Una de las principales aportaciones respecto a este tema se encuentra en la tesis doctoral Adaptación cinematográfica y traducción intersemiótica. Estudio de El nombre de la rosa a partir de las versiones italiana, francesa, inglesa y española (García, 2002).
} 
norte de Italia. Como indica Umberto Eco, Guillermo de Baskerville es un personaje envuelto en una trama detectivesca cuya erudición e inteligencia lógica lo convierten en un alter ego de Sherlock Holmes ${ }^{8}$, así como de las figuras históricas de Guillermo de Occam y Roger Bacon:

Necesitaba un detective, a ser posible inglés (cita intertextual), dotado de un gran sentido de la observación y una sensibilidad especial para la interpretación de los indicios. Cualidades que sólo se encontraban dentro del ámbito franciscano, y con posterioridad a Roger Bacon; además, sólo en los occamistas encontramos una teoría desarrollada de los signos. [...] Sólo en Bacon y en Occam los signos se usan para abordar el conocimiento de los individuos (Eco, 1984, p. 11).

El motivo del viaje de Guillermo de Baskerville, junto a su discípulo, es que los franciscanos y los delegados del papa deben tener un encuentro en la abadía para tratar sus diferentes posturas respecto a la pobreza del clero y a la separación de poderes entre el emperador y la autoridad papal. Por otro lado, la abadía es famosa por su biblioteca, uno de los espacios cruciales a través de los que se desarrolla la película, al igual que sucede con la novela. La biblioteca es un sitio prohibido, salvo su scriptorium, y está custodiada por Malaquías y Berengario (su ayudante), pero la figura crucial respecto a su protección es la del anciano Jorge de Burgos', un monje ciego español cuyas posturas se alejan de las de Guillermo, con un desenlace entre ambos que tendrá lugar entre el fuego que recorrerá los anaqueles de aquel laberíntico lugar. Durante la estancia en la abadía, Guillermo y su aprendiz presencian el fallecimiento de distintos monjes a través de extrañas circunstancias. Se trata de muertes fruto de una serie de infortunios que ya se habían iniciado antes de que los protagonistas llegaran al espacio abacial, relacionándose con la existencia de un libro envenenado, concretamente el segundo libro de Poética de Aristóteles, que habla sobre la comedia. Mientras el miedo se despliega por todo el lugar y sobre sus monjes, procedentes de distintas zonas geográficas (un factor multilingüe), el delegado del papa e inquisidor francés Bernardo Gui ${ }^{10}$ llega a la abadía, donde emprende un proceso inquisitorial sobre los sospechosos principales, entre los que se

\footnotetext{
8 Además de su apellido, en alusión a Sir Charles Baskerville, personaje creado por Arthur Conan Doyle; y el nombre de Adso recuerda fonéticamente al de Watson, ejerciendo ambos las funciones de cronistas, bajo diferentes matices.

${ }_{9} \mathrm{Su}$ nombre fue un homenaje al escritor Jorge Luis Borges (Eco, 1984, p. 12).

${ }^{10}$ El personaje existió realmente, siendo uno de los inquisidores más famosos en España, junto a Tomás de Torquemada (Cuéllar, 2018, p. 589).
} 
encuentra una campesina (de nombre desconocido) con la que Adso tiene un despertar amoroso. Este acontecimiento cobra mayor protagonismo en la obra audiovisual que en la novela. Además, la trama policíaca es la base fundamental de la película, alejándose ligeramente de las disquisiciones filosóficas, históricas y teológicas que recorren la novela de Umberto Eco, aunque cabe recordar que el semiólogo señaló que "la pregunta fundamental de la filosofía [...] coincide con la de la novela policíaca: ¿quién es el culpable?"11 (Eco, 1985, p. 23). Sin entrar en mayor profundidad acerca de la historia, cabe destacar otros personajes: Abbone, abad italiano de la congregación benedictina de la abadía; el italiano Ubertino da Casale $^{12}$, uno de los jefes espirituales de los franciscanos; Venancio, traductor de griego (con especial dedicación a las obras de Aristóteles); así como los italianos Remigio, cillerero de la abadía, y Salvatore, un grotesco y jorobado monje (interpretado por Ron Perlman), al que regresaremos por su peculiar modo de hablar.

\section{La traducción audiovisual de El nombre de la rosa}

La versión original de El nombre de la rosa se rodó principalmente en inglés (con sus variables multilingües), siendo el mismo idioma utilizado para escribir el guion literario ${ }^{13}$, el cual hizo de nexo interlingüístico entre la novela de Umberto Eco, escrita originariamente en italiano, y su adaptación cinematográfica, donde participaron los guionistas Andrew Birkin, Gérard Brach, Howard Franklin y Alain Godard ${ }^{14}$. La película fue una co-producción entre Alemania, Francia e Italia, sobre todo a través de la productora alemana Constantin Film, consensuándose el inglés como lengua vehicular ${ }^{15}$. Como indica Anne Jäckel, esta circunstancia es frecuente en las producciones europeas, ofreciendo una mayor difusión a nivel internacional:

\footnotetext{
${ }^{11}$ Se conoce como trama Whodunit (contracción de Who has done it?).

${ }^{12}$ Se trata de otro personaje histórico que vivió durante la Edad Media (Eco, 1985, p. 32).

13 Guion disponible en los apéndices de la tesis doctoral Adaptación cinematográfica y traducción intersemiótica. Estudio de El nombre de la rosa a partir de las versiones italiana, francesa, inglesa y española (García, 2002, pp. 803-921). En el guion se descubren escenas (como la número 71), que no aparecen finalmente en la película, de ahí también la importancia de aplicar la traducción sobre la obra audiovisual final.

${ }_{14}$ Ficha técnica disponible en https://imdb.to/2EUj8MP [Última consulta: 03/01/19].

${ }_{15}$ Cumpliendo las mismas funciones que, curiosamente, en el pasado habría ofrecido el latín.
} 
Shooting in English is regarded by European film producers as a way of breaking into the English-language market, the largest in the world in terms of purchasing power. [...] In Germany, where audiences are accustomed to watch dubbed films, German producers have long made English-language features. Bernd Eichinger (Constatin Film) made his name producing the films of Jean-Jacques Annaud, The name of the rose, and Bille August, The house of the spirits (Jäckel, 2001, pp. 7375).

Debido a que los personajes principales proceden de lugares diferentes, determinar qué lengua franca habría resultado más verosímil supone una labor compleja. De hecho, se debe tener en cuenta que la historia es narrada por Adso, cuya lengua nativa es la alemana. No obstante, el inglés es la lengua origen, empleando (además de repeticiones, interrupciones y otros recursos propios de la espontaneidad de la oralidad), determinadas variaciones lingüísticas del inglés antiguo, lo cual favorece al contexto medieval; con frases, por ejemplo, como "Thy will be done, my Lord", donde los franciscanos pronuncian el arcaico término "Thy", que actualmente ha sido substituido por "Your" (F2) (Brinton \& Closs, 2005, p. 26).

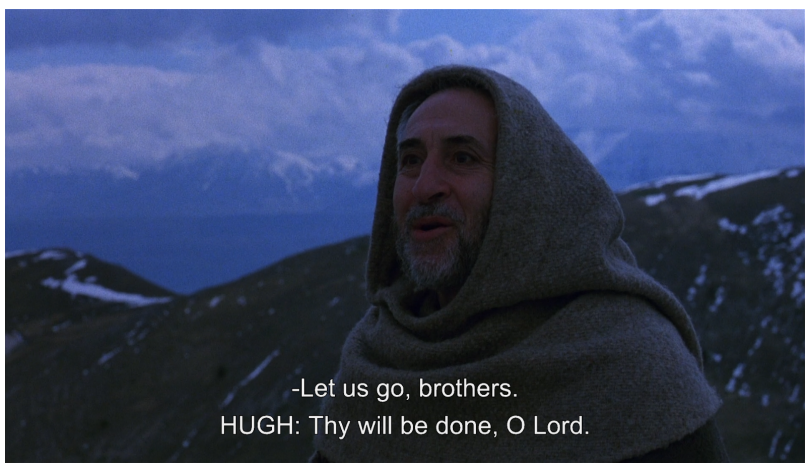

F2. Fotograma de El nombre de la rosa (1986). Constantin Film (C).

Por otro lado, la presencia del latín es un hecho relativamente frecuente en el cine $^{16}$. En el caso de El nombre de la rosa, se trata de otro de los idiomas con mayor presencia en su metraje, ya que fue la lengua vehicular de los espacios litúrgicos durante la Edad Media ${ }^{17}$, dotando a la obra de mayor verosimilitud, al igual que hizo Umberto Eco en su novela. Además, el latín también se aprecia por escrito; por ejemplo, cuando Guillermo observa los libros del scriptorium o de la

${ }_{16}$ Presente en títulos como Calígula (Tinto Brass, 1979), Sin noticias de Dios (Agustín Díaz Yanes, 2001), o La pasión de Cristo (The passion of the Christ, Mel Gibson, 2004).

${ }_{17}$ Empleada, además, en los cantos gregorianos, también presentes en la película. 
biblioteca, donde se reconocen algunas construcciones lingüísticas. Asimismo, en uno de sus planos se lee la frase "Stat rosa pristina nomine nuda tenemus" (F3), siendo muy similar a la reflejada en la novela ${ }^{18}$.

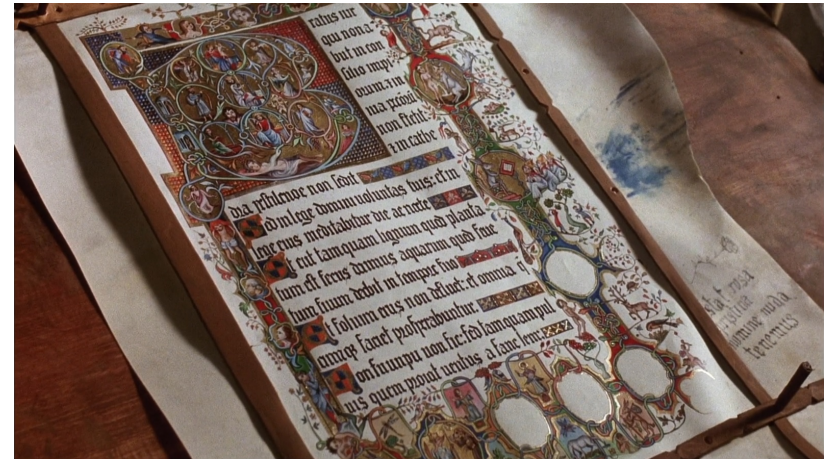

F3. Fotograma de El nombre de la rosa (1986). Constantin Film (C).

La incorporación del latín puede condicionar, de manera anticipada, la necesidad de la subtitulación posterior, permitiendo que el espectador capte la totalidad de la información que se desea transmitir. Se trata de una situación presente en determinados momentos de la película. Sin embargo, hay ocasiones en las que estos diálogos no aparecen subtitulados. Por ejemplo, cuando Guillermo y Adso llegan a la abadía hay un intercambio de saludos con uno de los monjes:

- Monje: Benedicamus domino.

- Guillermo: Deo gratias.

Lo mismo sucede cuando el abad Abbone accede a la celda de Guillermo y le da la bienvenida a la abadía:

- Abad Abbone: Pax vobiscum.

- Guillermo: Et cum spiritu tuo.

Se trata de situaciones que, debido al contexto comunicativo, se sobreentiende el significado de las palabras (Martínez, 2008, p. 16). Otro ejemplo diferente aparece en la escena en la que Adso revela el significado de varias palabras en latín que recorren el pergamino de Venancio, tras leerlas Guillermo previamente: is what?

- Guillermo: Manus supra idolum age primum et septimum de quatuor - Adso: With a hand above the idol, press the first and seventh of four.

${ }^{18}$ En la novela, la frase dice "Stat rosa pristina nomine, nomina nuda tenemus" (Eco, 1980, p. 678). En este caso, se habría omitido la palabra "nomina". 
Tampoco aparecen subtítulos, ya que son los mismos personajes los que traducen el idioma dentro de la trama. No obstante, no son las dos únicas lenguas utilizadas, pues en la abadía residen monjes procedentes de distintos países, dando lugar a un mundo posible cuyo multilingüismo viene marcado a través de la identidad geográfica de los personajes que habitan en él19. Como indica Jorge Díaz-Cintas, hay muchos cineastas que utilizan el multilingüismo como un recurso retórico para mimetizar la sociedad en la que se vive, reflejando de forma "realista" historias, por ejemplo, de encuentros interculturales (2015, p. 138). En la adaptación cinematográfica de El nombre de la rosa, las intervenciones en otras lenguas se dan, sobre todo, en las escenas de mayor tensión, desestabilizando la vida conventual. Este hecho es verosímil por ser circunstancias que rompen la tranquilidad de los personajes, incitando a que se expresen a través de sus lenguas nativas, lo cual enfatiza el desasosiego ${ }^{20}$. Por ejemplo, encontramos casos de este tipo cuando Guillermo se reúne con sus compañeros franciscanos, que hablan en inglés e italiano, traduciéndose incluso entre ellos (y en tales casos, omitiéndose los subtítulos); o en la secuencia en la que varios sirvientes avisan al abad Abbone acerca de un nuevo crimen. Éstos gritan en su lengua nativa italiana omitiéndose los subtítulos, lo cual potencia la sensación de confusión: inaudita.

- Sirviente 1: Una calamità, un'altra calamità ci ha colpito, una cosa padre.

- Sirviente 2: Padre, è sucesso un drama al porcile. Venite, venite presto, Otro caso particular es la lengua griega, también presente en la obra. Cuando Guillermo descifra el pergamino escrito en este idioma, éste se adapta a L1 mediante subtítulos, pues el personaje lee directamente las pequeñas letras griegas diciendo "Ponidoris idonem puestar", mientras que los subtítulos las traducen como "Use vulgar people. Take pleasure of their defects". A continuación, Guillermo advierte que el pergamino huele de forma extraña, y al acercarlo a la llama de una vela, aparecen nuevos caracteres, representando un

\footnotetext{
19 Salvo excepciones, como la del personaje de la campesina o de los sirvientes (que por contexto sociocultural no habría sido verosímil), la mayoría de personajes están construidos de tal manera que hablan, o potencialmente pueden hablar, más de una lengua.

${ }_{20}$ Como señala Núria Martínez, el multilingüismo cinematográfico también se suele utilizar para reflejar la angustiosa sensación de no entender al otro, fruto del contacto de distintos idiomas y culturas entre sí (2008, p. 6).
} 
código zodiacal (F4). Se trata de una escena que ejemplifica cómo el código icónico y lingüístico tienen diferentes funciones (Martin, 2002, p. 187), y si se elimina uno de éstos, desaparece el valor narrativo de la historia ${ }^{21}$.

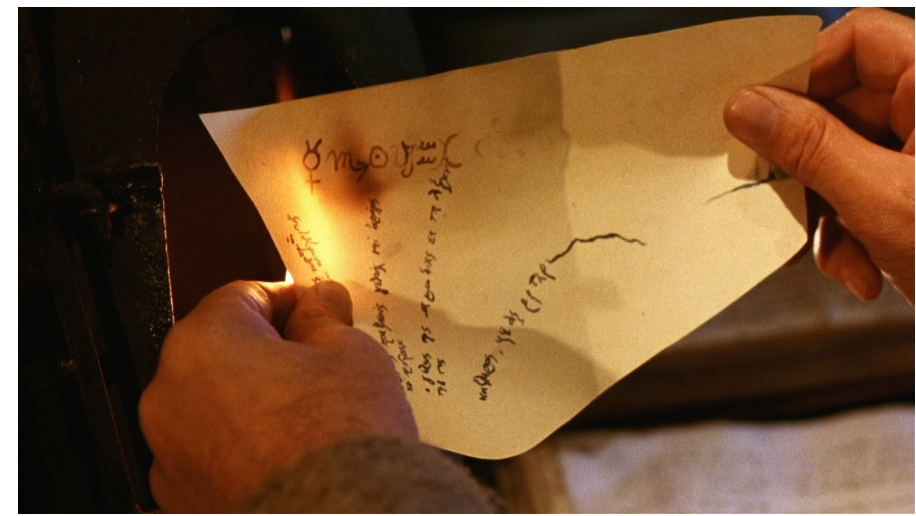

F4. Fotograma de El nombre de la rosa (1986). Constantin Film (C).

Por otro lado, los diálogos de Salvatore son una combinación babeliana del inglés, latín, español, francés, alemán e italiano, ya que el personaje "hablaba todas las lenguas, y ninguna. O sea que se había inventado una lengua propia utilizando jirones de las lenguas con las que había estado en contacto" (Eco, 1980, p. 61). Cuando Salvatore habla, se puede reconocer, en mayor o menor medida, lo que intenta comunicar, pronunciando, además de su reiterado "Penitenziagite!", frases como "Por favor, no! I am swearing it, nobody else", o "Praego, no burn Salvatore". Se trata de un carácter distintivo, cuyas intervenciones no contienen un proceso traductológico mediante subtítulos, a pesar de que en ocasiones emplee una única lengua, como sucede cuando está a punto de arder en la hoguera y canta en italiano.

Mediante datos cuantificados, en la versión original de la película aparecen siete lenguas diferentes: inglés, latín, italiano, griego, francés, alemán y español. En el caso del francés y alemán, éstos aparecen puntualmente, mientras que el español se incorpora en los diálogos de Salvatore (combinado con las lenguas ya citadas), y cuya particularidad lingüística permite que se considere una lengua inventada ${ }^{22}$. Así, la lengua inglesa corresponde a L1, mientras que las restantes L3 se traducen a L3 $3^{\mathrm{TT}}$ mediante la adaptación de subtítulos en L1 o sin cambios

\footnotetext{
${ }^{21}$ Además de contener una función metalingüística donde se acentúa la naturaleza del lenguaje, también presente en otras escenas.

${ }_{22}$ Estaría basada en L1, pero conteniendo también otras lenguas naturales diferentes como base y sin una construcción premeditada, propia de las artlangs y las conlangs.
} 
(Corrius \& Zabalbeascoa, 2011, p. 120). En consecuencia, las apariciones de L1 y la llegada de $\mathrm{L}^{\mathrm{TT}}$ desde $\mathrm{L} 3^{\mathrm{ST}}$, con o sin subtítulos, se cuantifican mediante la aportación del siguiente esquema ( $\left.\mathrm{F}_{5}\right)$ :
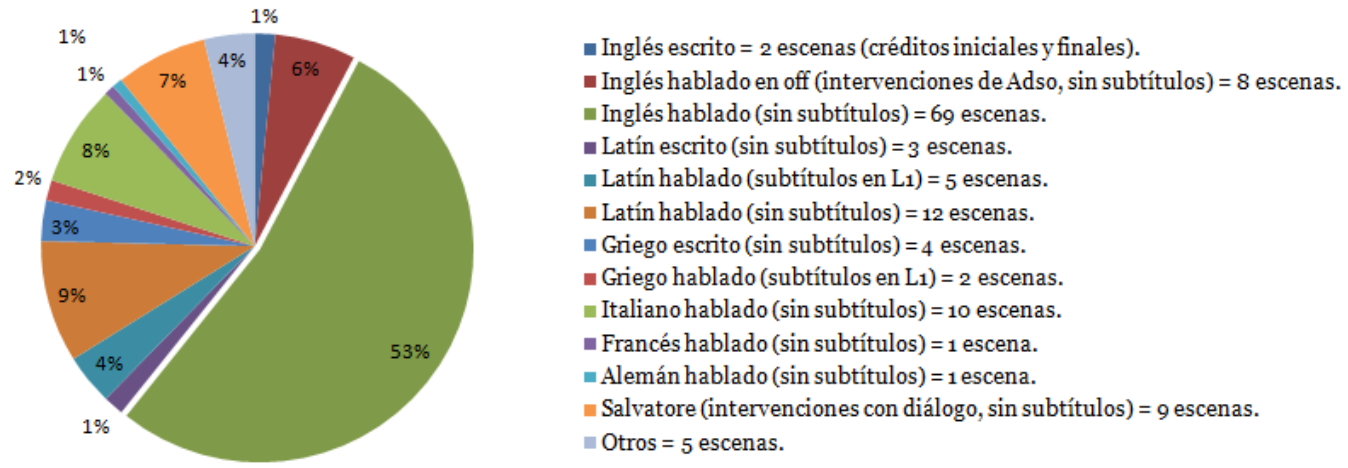

F5. Lenguas que aparecen en la versión original de El nombre de la rosa (1986).

Fuente: elaboración propia.

Tras contabilizar 99 escenas dentro de la película, en 69 de ellas aparece L1 hablada, ya sea dentro o fuera de campor23; mientras que Adso interviene en off (narrando desde su vejez en L1), en 8 momentos. También cabe matizar que en el latín hablado sin subtítulos se han incluido 8 escenas de cantos gregorianos, por lo que únicamente habría 4 escenas de diálogos en latín sin subtitular. Por otro lado, el italiano, francés y alemán no han llegado a L $3^{\text {TT }}$ mediante subtítulos; y en el caso de "Otros" se hace alusión a determinados momentos en los que los gritos de varias lenguas al unísono (y sin subtítulos) impiden determinar cuáles se están pronunciando, sobre todo cuando entran en juego las llamas de la Inquisición (aunque se deduzca que sean interacciones de las ya citadas). Así, y considerando que en una escena puede intervenir más de una lengua, se descubre que nos encontramos ante una obra multilingüe cuyo proceso traductológico no ha sido aplicado por igual a todas las L3, aportando subtítulos únicamente para adaptar a L1 determinadas apariciones orales del latín y griego, pero manteniendo sin cambios el resto de intervenciones ${ }^{24}$, lo cual no impide el favorecimiento de su verosimilitud, contextualización histórica y narratología.

\footnotetext{
23 Hay momentos donde su uso fuera de campo es fundamental (por ejemplo, cuando Guillermo y Adso se pierden en el laberinto de la biblioteca).

${ }^{24}$ Incluyendo el inglés por escrito, que resultaría redundante.
} 


\section{Apreciaciones sobre el doblaje español}

El doblaje español de El nombre de la rosa fue dirigido por Rogelio Hernández bajo la traducción de Guillermo Ramos ${ }^{25}$. Aunque entre el traductor y la obra debe existir un proceso de negociación (Eco, 2003, p. 10), en muchas ocasiones es relativo, viéndose condicionado por variables que generan deficiencias en la fidelidad traductológica. Recordemos, por ejemplo, el caso de la película Shrek (Andrew Adamson y Vicky Jenson, 2001), del que Mabel Richart reflexiona lo siguiente:

$\mathrm{Si}$, por poner un ejemplo, un investigador se encuentra ante la tesitura de analizar el doblaje de un film como Shrek (2001), y llega a una secuencia en la que la princesa Fiona lanza un eructo, semejante al que acaba de lanzar el personaje del ogro, ¿cómo explicará que el comentario del asno "She's as nasty as you are" haya sido traducido en la versión española por un «ahora vas y los cascas» absolutamente ajeno al sentido de la oración inglesa? Hará bien en hablar de la tendencia del doblaje español a introducir latiguillos propios de los humoristas encargados del doblaje [...] Pero al actuar de ese modo, cometerá un error en cuanto a lo que el doblaje de esa oración ha sido en realidad (Richart, 2008, pp. 302-303).

Desde una perspectiva prescriptivista, este caso sería una aberración, mientras que el decriptivismo apreciaría que el énfasis se ha puesto en el efecto humorístico (Botella, 2007, pp. 10-11). El doblaje de El nombre de la rosa no se vio afectado por este tipo de alteraciones. Además, aunque la película también se dobló en francés, alemán e italiano, el doblaje español es, como señala Francisca García, el que más se acerca a la versión original:

La versión española es la que, sin duda alguna, más se acerca a la versión original inglesa, y aquella en la que se han producido menos cambios en el proceso de doblaje. Aparecen exactamente las mismas escenas, y la intervención de los personajes no sufre alteración alguna (García, 2002, p. 720).

No obstante, aunque su traducción suscite un proceso natural, espontáneo e idiomático (Carriles, 2016, p. 14), también posee restricciones formales, lo cual implica adaptarse en términos descriptivistas. Por ejemplo, cuando Adso llega a

${ }_{25}$ Ficha técnica del doblaje español disponible en <https://bit.ly/2Sisfdt> [Última consulta: 03/01/19]. 
la abadía, unos monjes dejan caer agua limpia sobre sus manos mientras se escucha su voz en off:

- Adso L1: May my hand not tremble now that I start to relive the past / and revive the feelings of uneasiness that oppressed my heart / as we entered the battlements.

- Adso L2: Ojalá mi mano no tiemble ahora que me dispongo a narrar el pasado / Y a revivir la sensación de desasosiego que oprimía mi corazón / mientras penetrábamos en aquellos muros.

- Subtítulos L2: Que no me tiemble el pulso ahora que empiezo a revivir el pasado / así como el desasosiego que oprimió mi corazón/ cuando atravesamos las almenas.

Los subtítulos aparecen en tres bloques, a medida que se escucha el diálogo en off. El doblaje desde L1 a L2 es considerablemente fiel, a excepción del término battlements, que aparece como muros, en lugar de almenas, que sería su traducción literal y que, además, es como llega en los subtítulos (también más abreviados, concretamente el segundo y tercer bloque, debido a la restricción de caracteres). La voz en off de Adso se escucha en ocho ${ }^{26}$ escenas de la película, y este factor evita la sincronización labial, aunque se tiene en cuenta la duración de cada plano como restricción. Otro ejemplo se da cuando el abad Abbone le pregunta al anciano Jorge de Burgos qué opina sobre la llegada de Guillermo, en relación a que descubra el reciente asesinato en la abadía:

- Abad Abbone L1: What is your opinion, venerable Jorge?

- Jorge de Burgos L1: Dear brethren / I leave such worldly matters to younger men.

- Abad Abbone L2: ¿Qué opináis vos, venerable Jorge?

- Jorge de Burgos L2: Amados hermanos / Yo dejo los asuntos mundanos para los más jóvenes.

- Subtítulos L2: ¿Cuál es su opinión, venerable Jorge? / Mi querido hermano / Yo dejo los asuntos terrenales a hombres más jóvenes.

En este caso, el doblaje en lengua meta traduce younger men como los más jóvenes, cuya traducción literal es hombres más jóvenes, siendo como aparece en L1 y en los subtítulos L2. A diferencia del ejemplo anterior, el doblaje de esta escena está sujeto a restricciones de sincronización labial, pudiendo resultar la principal causa de adaptación de expresiones, y en este caso sería procedente por la ausencia de mujeres entre los monjes. Asimismo, los subtítulos del primer

\footnotetext{
${ }^{26}$ En los mismos momentos que en la versión original.
} 
diálogo de Jorge llegan como "Mi querido hermano", cuando en L1 y L2 se expresa en plural, tratándose de un posible error (traduciendo desde el guion original, sin la imagen) o de un acto deliberado. De estos factores se colige que el guion ha tenido cierto protagonismo en la subtitulación, ya que a lo largo de todo el metraje aparecen frecuentemente casos muy similares (como la subtitulación de battlements como almenas, y no como muros), donde, además, la coincidencia de L2 con L2 subtitulada no habría supuesto una restricción de caracteres, y sin embargo, existen este tipo de variaciones. Por ejemplo, y dentro de este último caso expuesto, el abad Abbone dice en L2: "¿Qué opináis vos, venerable Jorge?", mientras que en los subtítulos se lee: "¿Cuál es su opinión, venerable Jorge?", lo cual implica un aumento de tres caracteres respecto a L2, traduciéndose el subtítulo literalmente desde L1. Además, al igual que en la versión original se hace uso de un inglés antiguo que evoque los ecos de la Edad Media, en el doblaje español también se adoptan ciertas expresiones que mantienen el mismo tono. Por ello, es frecuente que los personajes utilicen vocablos como "os" o "vos", como en este caso, aunque se haya perdido en la subtitulación. Respecto a las intervenciones de L3, y teniendo en cuenta las restricciones expuestas (que se aplicarían a toda la obra), ésta sigue el mismo esquema que en la versión original, existiendo algunas excepciones. Así, el proceso de traducción en español queda cuantificado bajo el siguiente esquema (F6):
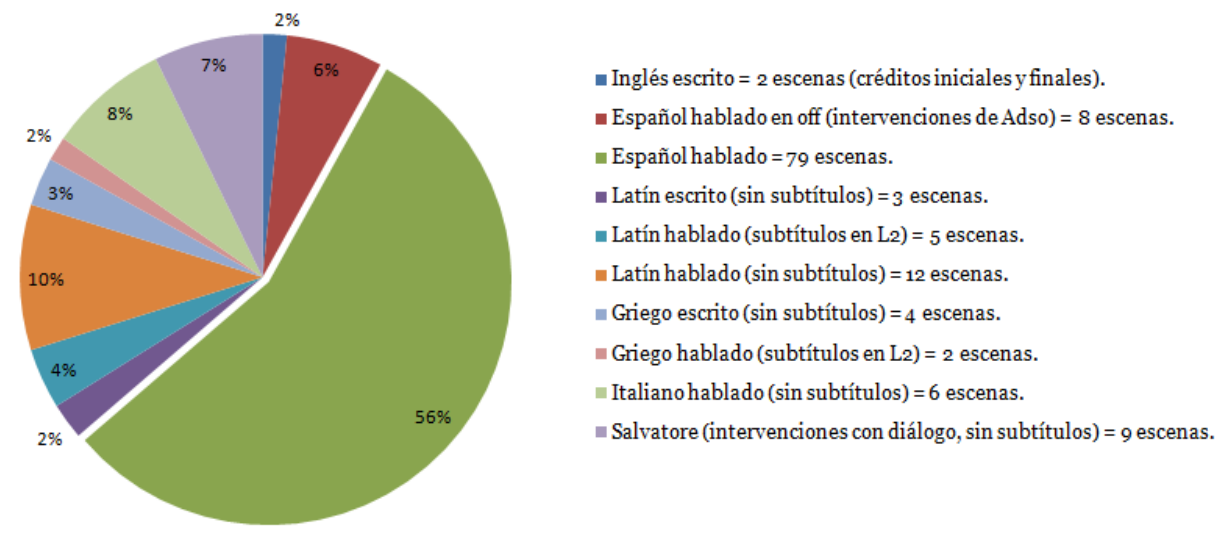

F6. Lenguas que aparecen en el doblaje español de El nombre de la rosa (1986).

Fuente: elaboración propia.

Manteniéndose las 99 escenas de la versión original, se descubre que en el doblaje español aumentan de 69 a 79 el número de escenas en las que L1 ha sido traducida 
a L227. Este hecho se debe a tres motivos. El primero es que las dos intervenciones en francés y alemán (L3 $\left.{ }^{\mathrm{ST}}\right)$ se han neutralizado, doblándose a la lengua meta. El segundo es que las escenas con diálogos en italiano $\left(\mathrm{L}_{3}^{\mathrm{ST}}\right)$ se han reducido de 10 a 6. Esas cuatro intervenciones en italiano también se han neutralizado, una de ellas eliminándose ${ }^{28}$ y las otras tres doblándose a L2. Y el tercer motivo es que las 5 intervenciones que no permitían identificar qué lenguas participaban también se han neutralizado a L2. Las alteraciones de las L3 citadas se dan con diálogos fuera de campo (sin necesidad de sincronización labial), y se recurre con frecuencia a la incorporación de nuevas líneas de diálogos (dentro de éstos), que enfatizan el código icónico, aunque se alejen de la fidelidad traductológica. Respecto a la presencia de la voz en off de Adso, así como las apariciones del inglés escrito, latín y griego, el proceso traductológico se mantiene bajo los mismos mecanismos que en la versión original, subtitulando en L2 lo que en la versión original se ha subtitulado en L1 (y con la ausencia de subtítulos en las mismas escenas). En el caso de los diálogos de Salvatore, éstos tampoco aparecen subtitulados, manteniendo su rasgo más definitorio y su valor narrativo, aunque en este caso $\mathrm{L}_{3}^{\mathrm{TT}} \neq \mathrm{L} 3^{\mathrm{ST}}$, ya que algunas de sus expresiones en $\mathrm{L} 1$ sí que han llegado dobladas a L2.

Estas apreciaciones son las que se considerarían más relevantes en cuanto al doblaje español de El nombre de la rosa, sin entrar en detalles respecto a cada línea de diálogo, lo cual implicaría una extensión alejada del presente formato. Así, y como indica Jorge Díaz-Cintas, en este tipo de producciones multilingües, la decisión de traducir o no las diferentes lenguas que aparecen depende, generalmente, del valor narrativo que el multilingüismo adquiere en la película (Díaz-Cintas, 2015, p. 143). En este caso, nos encontramos con un modelo cuya traducción en español ha mantenido determinadas variaciones lingüísticas favoreciendo el valor narrativo de la historia, aunque en el proceso traductológico hayan desaparecido parte de éstas.

\footnotetext{
27 En las escenas 46 y 48, las voces de doblaje de Adso, Guillermo y Ubertino cambian momentáneamente de tono, siendo escenas incluidas en el DVD (ausentes en el VHS).

${ }^{28}$ Cuando Guillermo y Adso están llegando a la abadía, en la versión original se oyen diálogos en italiano fuera de campo que en la versión doblada desaparecen.
} 


\section{Conclusión}

La traducción audiovisual en el cine multilingüe adquiere ciertos matices donde los códigos visuales, sonoros y gráficos convergen, necesitando los tres elementos para la comprensión total del mensaje. Por ello, con este análisis queda refrendada nuestra hipótesis de partida. Si la obra conservara únicamente L1 (o L2, en su caso) habría desaparecido su verosimilitud, contextualización histórica y narratología, acentuadas con la llegada de L3. El uso de diálogos originales diferentes al inglés (o al español, en su caso), contribuyen, junto al resto de elementos del lenguaje audiovisual, a contextualizar la historia en una época determinada, dotándola de veracidad e interculturalidad; y no como un elemento exótico, anecdótico o estereotipado. Los diálogos en latín implican restricciones en cuanto a la subtitulación, pero es la L3 con mayor presencia en la obra, ayudando a dicha contextualización (incluyendo los cantos gregorianos). Además, la supresión de determinadas escenas donde intervienen el latín o griego implicaría una complejidad narrativa para el avance de la trama. No obstante, existen restricciones que afectan al proceso de traducción, además de recordar que en la versión doblada en español desaparecen dos lenguas (francés y alemán), si bien es cierto que se trata de intervenciones que no alteran a la obra en su totalidad; lo cual también sucede con la neutralización del italiano, ya que se mantienen varias intervenciones que favorecen el multilingüismo y la sensación de confusión.

Aunque la aparición del DVD haya dado lugar a que el público elija cómo desea consumir la obra (facilitándose así su consumo), el cine multilingüe contiene este tipo de matices que conviene tener en consideración. De hecho, en la edición en DVD de El nombre de la rosa editada en España aparecen 16 subtítulos diferentes a elegir, con idiomas como el hebreo, el griego moderno o el turco, además del inglés para personas con discapacidad auditiva. Además, conviene recordar que la película fue rodada principalmente en inglés, pero Jean-Jacques Annaud ya sabía de antemano que el montaje final no sería la obra que se exhibiría al espectador. Era necesario que existiese un proceso previo de subtitulación. Se trata de un factor clave en su mundo posible, donde el mensaje audiovisual, de naturaleza multilingüe, requiere ser complementado a través de la palabra, y se debe tener en cuenta desde la elaboración del guion. De este modo, se comprende 
la totalidad del mensaje que Annaud transmite a los espectadores que se adentran en su abadía subtitulada.

\section{Referencias bibliográficas}

Agost, R. (2007). La traducción de la publicidad televisiva: la globalización, catalizadora de cambios en la estrategia traductora. Linguistica Antverpiensia, New Series - Themes in Translation Studies, 6, 295-314. Recuperado de https://bit.ly/2EQPZ5k

Bordwell, D. \& Thompson, K. (2003). El arte cinematográfico. Barcelona: Paidós.

Botella, C. (2007). Aproximación al estudio del doblaje y la subtitulación desde la perspectiva prescriptivista y la descriptivista: la traducción audiovisual. Tonos digital: Revista electrónica de estudios filológicos, 13. Recuperado de https://bit.ly/2iVOx4r

Brinton, L. J. \& Closs, E. (2005). Lexicalization and Language Change. Cambridge, Reino Unido: Cambridge University Press.

Brychová, A. (2017). Multilingualism as a Chance - A Set of Conferences About the Promotion of Multilingualism. Orbis Scholae, 11(3), 123-125. Recuperado de https://bit.ly/2ESRTlM

Carriles, T. (2016). Dificultades de traducción de las películas multilingües. El caso de La terminal (Trabajo final de grado). Madrid: Universidad Pontificia de Comillas. Recuperado de https://bit.ly/2RjvW59

Chaume, F. (2014). Cine y traducción. Madrid: Cátedra.

Coker, L. (2016). Tolkien's Linguistics: The artificial languages of Quenya and Sindarin. The National Conference on Undergraduate Research (NCUR). University of North Carolina, Asheville, pp. 1242-1249. Recuperado de https://bit.ly/2rSprrF

Corrius, M. \& Zabalbeascoa, P. (2011). Language variation in source texts and their translations. The case of L3 in film translation. Target - International Journal of Translation Studies, 23(1), 113-130. DOI: 10.1075/target.23.1.07zab

Cuéllar, C. (2018). Los dominicos y el cine: el subtitulado de películas multilingües. En Bueno, A. (Dir.). Los dominicos españoles $e$ iberoamericanos y la traducción (Traducción intersemiótica y artística), 3, 1131-1144. Granada: Editorial Comares. Recuperado de https://bit.ly/2rVdLV8

Díaz-Cintas, J. (2015). Multilingüismo, traducción audiovisual y estereotipos: el caso de Vicky Cristina Barcelona. Prosopopeya. Revista de crítica contemporánea: Traducción, ideología y poder en la ficción audiovisual, 9, 135-161. Recuperado de https://bit.ly/2T9zaW7

Eco, U. (1980). Il nome della rosa. Milán: Bompiani.

Eco, U. (1984). Postille A Il Nome Della Rosa. Milán: Bompiani. 
Eco, U. (2003). Dire quasi la stessa cosa. Esperienze di traduzione. Milán: Bompiani.

García, F. (2002). Adaptación cinematográfica y traducción intersemiótica. Estudio de El nombre de la rosa a partir de las versiones italiana, francesa, inglesa y española (Tesis doctoral). Málaga: Universidad de Málaga. Recuperado de https://bit.ly/2yvlEo4

Jäckel, A. (2001). Shooting in English? Myth or necessity? En Gambier, Y. \& Gottlieb, H. (Eds). (Multi)Media Translation: Concepts, Practices, and Research. Ámsterdam: John Benjamins, 73-75.

Martí, J. L. (2010). Cine independiente y traducción. Valencia: Tirant Lo Blanch.

Martin, M. (2002). El lenguaje del cine [1955, $5^{\mathrm{a}}$ ed.]. Barcelona: Gedisa.

Martínez, N. (2008). La subtitulación de una película multilingüe: Ladies in Lavender. Barcelona: Universidad Pompeu Fabra. Recuperado de https://bit.ly/2EOwJ7I

Mendoza, M. (2015). El doblaje y el español neutro en las películas de animación de Disney (Trabajo final de grado). Barcelona: Universidad de Vic. Recuperado de https://bit.ly/2GGorOH

Richart, M. (2008). Algunas reflexiones en torno a la traducción audiovisual. En Actas del II Congreso Internacional de Lengua, Literatura y Cultura de E/LE: Teoría y práctica docente. Onda: JMC, 295-310. Recuperado de https://bit.ly/2CE2YFp

\section{Filmografía}

Adamson, A. \& Jenson, V. (2001). Shrek. Estados Unidos: DreamWorks Animation / DreamWorks SKG / Pacific Data Images.

Annaud, J. J. (1986). Der name der rose. Alemania, Francia e Italia: Constantin Film / Zweites Deutsches Fernsehen / Cristaldifilm / Radiotelevisione Italiana / Les Films Ariane / France 3 Cinéma.

Avery, J. (2018). Overlord. Estados Unidos: Bad Robot / Paramount Pictures.

Besson, L. (1997). Le cinquième élément. Francia: Gaumont.

Brass, T. (1979). Calígula. Italia: Penthouse Films International.

Cameron, J. (2009). Avatar. Estados Unidos: 20th Century Fox / Lightstorm Entertainment / Giant Studios Inc.

Coppola, S. (2003). Lost in translation. Estados Unidos: Focus Features / American Zoetrope / Elemental Films.

Dance, C. (2004). Ladies in Lavender. Reino Unido: Scala Productions.

Díaz Yanes, A. (2001). Sin noticias de Dios. España: Cartel / Tornasol Films / Flamenco Films / DMVB Films / Eyescreen / Ensueño Films / Telemadrid.

Gibson, M. (2004). The passion of the Christ. Estados Unidos: Newmarket / Icon Productions.

González Iñárritu, A. (2006). Babel. Estados Unidos: Paramount Pictures / Paramount Vantage / Anonymous Content / Zeta Film / Central Films. 
Hughes, A. (2018). Alpha. Estados Unidos: Studio 8.

Spielberg, S. (2004). The terminal. Estados Unidos: DreamWorks Pictures.

Tarantino, Q. (2009). Inglorious basterds. Estados Unidos y Alemania: Universal Pictures / The Weinstein Company / Lawrence Bender / Neunte Babelsberg Film. 